\title{
RETRACTED ARTICLE: High-performance computing system and artificial language recognition in the visual application of intangible cultural heritage art design
}

\author{
Xiaodan Peng ${ }^{1}$ \\ Received: 10 June 2021 / Accepted: 2 August 2021 / Published online: 11 August 2021 \\ (C) The Author(s), under exclusive licence to Springer-Verlag London Ltd., part of Springer Nature 2021
}

The Editor-in-Chief and the Publisher have retracted this article because the content of this article is nonsensical. The peer review process was not carried out in accordance with the Publisher's peer review policy. The author has not responded to correspondence regarding this retraction. The online version of this article contains the full text of the retracted article as Supplementary Information.

Supplementary Information The online version contains supplementary material available at https://doi.org/10.1007/s00779-021-01619-z.

Xiaodan Peng

pengxd20212021@163.com

1 Guangdong Nanhua Industrial and Commercial Vocational College, Guangzhou 510507, Guangdong, China 